\title{
Resource Sharing or Cost Shifting?-The Unequal Burden of Cooperative Cataloging and ILL in Network
}

\section{Charles B. Lowry}

The values and reward system that characterize library cooperation are drawn from an environment quite different from that of the modern library network, which is founded on the shared cataloging/ILL utility. Reflecting as it does an earlier system of values about participation, the reward system for the technology-based network encourages use of but not contribution to the "national library database." This paper examines the dilemmas of participation in resourcesharing networks and proposes solutions based on shifting the inducements toward contribution by remunerating the contributing library for the unit cost of original cataloging and the suggested restructuring. The restructuring suggested is applicable to library network/utilities in general. However, OCLC's recently announced "contribution pricing" may serve as a model for changing the reward system, which is a prerequisite to preserve the "national library database" that the OCLC represents.

\section{COOPERATION-WHAT IS IT?}

In the post-World War II period, the concept of library cooperation has tended to focus on two primary and critical activities-shared cataloging and interlibrary lending. But in recent years, a more comprehensive notion of the dimensions of library cooperation has become essential to our lexicon. This extends right down to local cooperative activities and includes shared collection development, preservation, and training, particularly for technological purposes. ${ }^{1}$

To understand the dimensions of library cooperation today, we must understand the modern development of library networks. JoAn Segal notes that "there are implicit levels of networking .... of several sorts: type-of-library networks, sizeof-library networks, and geographical- area networks at various aggregations of area. $^{2}$

Recently Edward Walters has applied the social sciences concept of institutions to provide an organizing model to group the variety of organizations that we call library systems, networks, consortia, associations, and cooperatives. He has identified five forms of networking: (1) the unit cost networks such as OCLC or RLIN, with the size and revenue sources to raise substantial capital for development; (2) the multistate regional auxiliary enterprise networks such as AMIGOS or SOLINET, with their low capital investment and fee-based assessment with a more limited ability to amass capital; (3) the authority-sanctioned networks such as ILLINET and FEDLINK established by governments or government agencies that have jurisdiction and draw on those au-

Charles B. Lowry is Director of Libraries at the University of Texas at Arlington, Arlington, Texas 76019. This article is based on a paper delivered as a keynote address for a miniconference on the Cost of Cooperation in Academic and Research Libraries jointly sponsored by the University of North Texas, School of Library and Information Sciences, and AMIGOS Bibliographic Council held in Denton, Texas, May 11, 1988. 
thorities for their power to coerce the acceptance of standards and as a source of capital for new projects; (4) the discipline and type-of-library networks that are created for the purpose of sustaining either a discipline, (e.g. law, medicine, and agriculture), or an institutional form (e.g. university or corporation); and (5) local consortia or proximity networks that are founded and sustained because geographical proximity makes library cooperation more timely and often more effective. These latter vary greatly in the kinds of organizations they include, size, governance, and programs.

Each of the five types of library networks is part of a national library "network picture" that is interlocking in its services and belief systems. One cannot talk about a type of network without defining its relationship with the others. ${ }^{3}$ Moreover, most academic libraries are members of several of these types of networks. The University of Texas at Arlington and the University of South Alabama-two libraries where the author has most recently been director-have been simultaneously members of four or five types. This degree of participation brings attendant cost and benefits. The question becomes "is the cost outweighed by the benefit?" Several problems arise in this networking environment because of the underlying assumptions we have about cooperation, and the need for managerial control based on a realistic cost model in our "not-for-profit industry." There are also numerous hidden or indirect costs to which no attention is paid as we work towards the abstract ideal of cooperation.

\section{DILEMMAS OF NETWORK RESOURCE SHARING}

It has been pointed out frequently that resource sharing in any type of network environment may be used by libraries as a prop to reduce their own obligations to build adequate local resources. ${ }^{4}$ Moreover, there is a growing concern among larger research libraries that the primary objectives they have for cooperating through utilities-cataloging and interlibrary loan-are heavily subsidizing services they neither need nor want. ${ }^{5}$ There is considerable anecdotal and some empirical evidence to illustrate that libraries, including members of ARL, take unfair advantage in relation to their contributions to network participation. The assumption is often made that research libraries with the largest budgets and collections are the largest ILL net-lenders. However, among those twenty-five ARL libraries with the largest budgets, only ten are among the top twenty-five net-lending libraries in ARL. Of the other fifteen, eleven are not among the ARL top forty largest lenders. Curiously, of the ARL libraries with the twenty-five largest collections, fifteen are not among the twenty-five largest lenders and eleven are not among the ARL top forty-exactly the same numeric result. By contrast, nine of the top twenty-five ILL net-lenders in ARL have budgets that are not among the ARL top forty, and eight of the top twenty-five net-lenders have collections which are not in the top forty. ${ }^{6}$ These striking numbers indicate clearly that the ethos of ILL resource sharing is not necessarily associated with either the largest budgets or collections. An examination of contributed cataloging would likely produce similar results. There certainly has been no lack of conjecture at OCLC Users Council meetings that libraries with extremely high search levels and low holdings and FTU use are "ripping off" the database.

\section{"Networking becomes more an eco- nomic decision than one of 'apple pie and motherhood.'}

Daily, library managers must refuse to acquire new journal titles, cut book expenditures, and in numerous ways decline to acquire materials for patrons because they do not have the money to do so. Only in the area of "free" ILL do we assume we can get something for nothing. Indeed, free ILL can become a straw man used in defense of inadequate budgeting for access to materials primary patrons need. 
Paul Gherman argues that "networking becomes more an economic decision than one of 'apple pie and motherhood.' Accordingly, the goal of 'the greatest good for the greatest number' is tempered by the recognition that nothing is free, by the desire to avoid exploitative imbalance of services between libraries, and by preference for contractual or cost-based transactions over open-ended moral commitment. ${ }^{\prime 7}$

Criticism of the value of network cooperatives comes not just from the academic research libraries but also from the public library sector. Notable among these is Thomas Ballard. He states that, "an entirely unsubstantiated belief in cooperative resource sharing as the best way to improve library services has been considered sufficient reason to spend millions of dollars. This is dogma-purely and simply." Ballard offers criticism at another level, calling into question the basic assumptions of cooperative network activities with a belief that "for the patron, bibliographic networking is merely a return to closed stack concept," and that the "levels of inter-library loan indicate that people really don't want everything. ${ }^{\text {,8 }}$ Such opinions from colleagues no doubt raise hackles among the majority in our profession. This occurs because of an intricate belief system that (1) no library has the resources to satisfy all its patrons' needs, (2) library cooperative efforts will fill the gap between patron needs and resources, (3) a national library network built from the bottom up is a self evident good, and (4) libraries have a democractic responsibility to minimize the gap between the information rich and the information poor. ${ }^{9}$ Library networking even received pontifical support when in 1982 "Pope John Paul II . . . expressed deep interest in the Theological Library Network founded . . . in Rome by 60 representatives of pontifical universities and other Catholic as well as non-Catholic institutions."

\section{SQUARING "BELIEF SYSTEMS" AND BEHAVIORS}

How do we reconcile our belief systems with the reality of behavior among institutional participants in library cooperation?
With the emergence in the 1970s of major bibliographic utilities containing large extraordinarily rich electronic databases, the foundation was laid for the development of a complex array of networking arrangements. Today, the local library cooperative is possible only as part of this larger scheme. These utilities came into existence and libraries became cooperating members for two primary reasons-to reduce the cost of cataloging library materials and to use the databases built in this process as a new vehicle for interlibrary lending. No one wants to go back to doing things pre-1970, because the utilities have been extraordinarily effective in helping libraries reduce the cost of labor-intensive manual systems. ${ }^{11}$ Nonetheless, there are inherent temptations in the way we structure member participation, which encourage libraries to ignore the belief system and to take advantage of their peers. Two examples of this structural problem-ILL and shared cataloging-are the focus of the balance of this paper. These two activities alone are fundamental illustrations of the great success of automated/electronic networks, and probably point the way to the most cost-effective cooperative activities of the future. ${ }^{12}$ However, they are not without flaws. In the discussion which follows, OCLC is the prominent example, but the other major bibliographic utilities are affected by similar conditions with the same results.

\section{INTERLIBRAY LOAN}

Interlibrary loan should properly be characterized as interlibrary sacrifice, because we have tended to focus narrowly when determining the cost on a tightly defined range of issues, including local staff time, equipment costs, lending charges by the utilities, charges from the lending library, success or fill rate, and turnaround time. ${ }^{13}$ These are not inconsequential issues, but they are not sufficient to help us in determining the real cost benefit of ILL cooperation or in defining new ways to establish an adequate added value to this service.

It has been frequently argued that the tradition of "free" interlibrary loan is no longer adequate in the electronic environment of the modern bibliographic utility 
and that small libraries will lose their initial euphoria over the good of participation as they approach net lending versus net borrowing. ${ }^{14}$ Herbert White recently stated that "our attitude comes from acceptance of interlibrary loan not as a pragmatic commodity, but as a moral precept .... This premise now conflicts directly with our evolving responsibilities as resourse managers accountable to those who fund us and those we serve directly. ${ }^{\prime 15}$ The problem, as he sees it, is that the lowest priority in ILL becomes lending our materials and the highest priority becomes borrowing materials for our patrons.

\section{"The pricing of OCLC/ILL charges from the perspective of actual costs or as an inducement to lend makes little sense."}

The ILL system as presently constituted tempts participants to make cooperation a one-way street, though many avoid the temptation. "The net lenders know who they are, and they also know that they provide far more than they receive. ${ }^{16}$ An example of the dilemma is UT Arlington Libraries' ILL Department which has long prided itself on handling an OCLC/ILL request within twenty-four hours and has a well-earned reputation for responding quickly. The net result is that lending is on the increase. If it were not for the fact that requests for borrowing have skyrocketed due to a major surge in doctoral education and externally funded research, UTA would have long since been a large netlender. In this situation, a library manager is faced with the dilemma of either adding staff and equipment to the ILL Department in order to meet demands to lend materials, or setting the principle that borrowing is the first priority and responses to requests to lend will be allowed only when all of the borrowing is done. If we were to adopt this stance, requests to borrow would bypass UTA in the OCLC queue and, before long, requests would begin to decline.
The pricing of OCLC/ILL charges from the perspective of actual costs or as an inducement to lend makes little sense. The borrowing charge is 83 cents, and the lending credit is 20 cents. There is no palpable difference between these two costs from OCLC's perspective, and certainly no reason to encourage lending at so insignificant a level. The 20 cents credit for lending does not even qualify as a sop, although OCLC's primary objective is to support system costs, not encourage ILL lending. Increasingly we hear calls for the actual "determination of cost honestly, in terms that meet the accounting criteria of the supplier whose perception is ultimately all that matters. Cost is not the same thing as price. ${ }^{\prime 17}$ A recent experiment by the Missouri State Library in which "lending libraries were reimbursed $\$ 5.00$ for each item loaned, above the number of items borrowed by that library" seems to point in a reasonable direction. ${ }^{18}$ Likewise, medical libraries participating in TALON pay a $\$ 4.00$ fee per item borrowed. But the determination of standard costs or the call for standard fees ${ }^{19}$ will take more than guesswork, and must include new cost elements which will be discussed below.

\section{SHARED CATALOGING}

It is curious that the cost structure of shared cataloging has not had the same scrutiny nor produced as much literature as ILL. There are two obvious omissions here. The first is that studies of pricing tend to focus on the surcharges added by regional networks to OCLC costs. ${ }^{20}$ These are of some importance, but they are not paramount since the surcharges are a small percentage of the total cost of cataloging and contribute to direct services of the regional networks. The credit on OCLC for original contributed cataloging is $\$ 1.00$ a record. Libraries participating in the "enhance project" receive $\$ 1.29$ for records which they upgrade.

One wonders how many libraries could demonstrate that $\$ 1.00$, or even a $\$ 1.29$ compensated them adequately for the expense of original cataloging. On the other hand, the OCLC charge for prime time use of a record in the database is $\$ 1.29$. If there ever was a disincentive to contribute origi- 
nal cataloging, this price structure is it. The truth is that utilities, particularly OCLC, have reaped the benefit of added value of cataloging supplied by libraries to their union databases. At present OCLC estimates that member input (including GPO and NAL) is about 76 percent of current cataloging in the OLUC (OCLC online union catalog).

Although libraries have viewed utilities as entities they have created to do work for hire, the reality is that libraries are supplying piece-work cataloging to the utilities at a sweat labor price which is resold to other libraries for a tidy sum. How do we correct these shortcomings and remove the temptation to reduce our costs at the expense of other libraries by waiting for some other library to assume the cost of original cataloging?

\section{COST-BENEFIT CRITERION AND UNIT COST METHOD}

The cost benefit criterion theme stated simply is that as a system changes its expected additional benefits usually must exceed its expected additional costs. ${ }^{21}$ There have been numerous calls for cost benefit or cost effectiveness analysis. This always sounds complex. Perhaps it can be simplified. ${ }^{22}$ Kaye Gapen says it is time to begin treating the "access cost" as equal to the "collection cost." Put another way, "There will be new choices to be made in smaller libraries between low fixed costs and high incremental costs per search strategy. Larger libraries are more likely to choose the high fixed cost and low incremental cost strategy at least for very commonly used datafiles.",23

Cost benefit would work something like this: a library borrowing on ILL pays to the lending institution a cost based on the high fixed cost experienced by the lending institution for maintaining materials in its collection and recovering them for lending purposes. Similarly, a library contributing original cataloging benefits from this labor in a manner equivalent to the effort and expense of its work. In either case, there is a positive inducement to cooperate and share collection resources or cataloging labor and no inducement to take advantage of the system.

The actual unit cost for ILL activities must be established in order to judge the cost benefit. "Techniques have been developed permitting uniform cost analysis for varying libraries. These techniques take into account the fact that nearly all the direct budget contributes to more than one service (book stock and technical services), are a kind of overhead, and that details of cost allocation depend on the actual levels of service rendered." ${ }^{24}$ Obviously, unit cost will vary from library to library, but a sample can provide a relatively standard method of determining unit costs. A good example of the unit cost method is the work done recently at Virginia Tech. ${ }^{25}$ How would this work in our electronic network environment? Put another way, how will unit cost be established and who will pay? Examples of ILL and cataloging help explain the use of the cost benefit and unit cost approach.

To use White's phrase, ILL is temporary acquisition. "The real decision is between permanent and temporary acquisition. Permanent acquisition costs more initially, but that cost is not repeated for each future use. Temporary acquisition costs less one time, but if it is repeated the costs reach an equal level., ${ }^{26}$ We should also recognize that each time a library lends through ILL it may lose an opportunity for its own patrons to use an item in which it has invested at high fixed cost. This happens in two ways. First, the item may not be on the shelf when the patron goes to look for it. Second, there is a loss due to wear-and-tear on the item which now has one less circulation in its expected "life span."

A recent in-house study entitled "Cost Data for the Virginia Tech Library" established the total cost of purchase and shelving monograph volumes at \$106 each and the total cost for purchase and shelving of serials volumes at $\$ 181$ each. This per item investment represents a finite number of uses, and each time a library lends materials to nonprimary patrons the net result is a potential loss on that investment. Assuming 25 circulations per item for a typical publishers book binding, Virginia Tech is dissipating $\$ 4.24$ per monograph for each ILL loan that it makes. ${ }^{27}$ Likewise, if a "class A" serial binding lasts 50 circulations, the loss per photocopy-loan 
amounts to $\$ 3.62$. Conversely, the borrowing library is saving an equal amount.

An ARL library lending 70,000 items per year (half books and half serial copies) has lost \$275,100 of its capital investment in collections. Using the unit cost method, a formula could be developed that factors in the lending libraries staff expenditures, periodical expenditures and monograph expenditures of over a five-year period. The staff expenditure would have to be indexed on the average salary for staff. Periodical expenditures would be indexed on the average cost per title and book expenditures on the average cost per volume. This would take into account regional differences in wages and the variable character of collecting costs depending on the relative emphasis in each institution on different types of materials. It might also be helpful to develop an index of collection size, because there is an implicit cost for maintenance, although this may be captured in the staff cost index. By gathering these statistics, annually libraries would provide the basis for establishing the unit cost for lending both photocopy and book stock. This unit cost would be an added value to the interlibrary loan transaction, which would be paid directly to the lending institution by the borrowing institution.

A palpable billing nightmare could be caused by such a system, but there is a simple way out. It has been suggested that "since OCLC already bills requestors for its own transaction fee, it could possibly expand that accounting capability to include collecting and disbursing ILL fees. ${ }^{\prime 28}$ At its March 16, 1989, meeting the AMIGOS Board voted to request formally that such a scheme of payment be incorporated into the OCLC "New System" design. That action was based on a white paper submitted by the AMIGOS ILL Policy Review Committee. The white paper proposes that each year participating libraries supply OCLC with their ILL charges based on type of materials. These ILL charges, or the actual unit cost, would be posted on the OCLC system in the name and address directory. Obviously, libraries would make borrowing choices, at least in part, based on these borrowing charges. When a library borrowed material, the unit cost (ILL charge) of the lending library would be added to the OCLC borrowing charge. On a monthly basis the difference between lending and borrowing costs would be reconciled for OCLC billing. This sort of system would not cause a billing and paying nightmare, but would eliminate one that currently exists for some libraries. For instance, a State of Texas payment voucher for ILL costs UTA Libraries, the University and the State more than $\$ 40.00$ in paperwork expenses just to pay the lending library as little as a dollar. Moreover, this sort of unit-cost system would not prevent libraries from continuing existing arrangements of reciprocal borrowing agreements if they chose to do so.

\section{"The real cost of original cataloging is significantly higher than the OCLC payment for original contributed cat- aloging or the 'enhance project.' "'}

Many libraries are moving toward unit cost recovery, whether they call it that or not. Furthermore, each library could choose to fund this real ILL acquisition cost or pass on the expense to their patrons. In any event, a library choosing in favor of a "high cost per transaction but a small fixed cost" would bear the responsiblity for that choice and Interlibrary Loan would cease to be Interlibrary Sacrifice. $^{29}$

The cost of cooperative cataloging presents a slightly different set of issues, but deserves much more discussion than it has received. The point was made earlier that the cost of original cataloging is significantly higher than the OCLC payment for original contributed cataloging or the "enhance project." Establishing the unit cost for cataloging in an individual library is probably not necessary. Instead, a sample of cost elements in cataloging for a number of libraries could be used to establish an average unit cost for original cataloging of different formats perhaps at a minimum 
of $\$ 50$ per title. Any library would be entitled to payment for its contributions to the OLUC based on these unit costs which would certainly be far higher than the present payment for original input.

When would a library be entitled to payment? There are several possibilities. Payment could be made at the time of the initial input of the record if the title had not already been cataloged or if the recataloging was being done by an "enhance" library. A better system would pay a library when the cataloging copy was used by another library, either by paying in a lump sum (e.g., \$50.00) or paying incrementally for each use of the record until the lump sum was reached (e.g., $\$ 5.00$ a use up to the maximum of $\$ 50.00$ ). The latter method has the advantage of letting re-use of the record establish its fair market value. This brings us to one final question. Who will pay the unit cost for this original cataloging? The point was made earlier that the added value for original cataloging is contributed by the member libraries, and at least in some measure it is represented in OCLC's corporate equity $\$ 49$ million or net worth. ${ }^{30}$ Thus, OCLC should pay the lion's share of this new unit cost.

\section{CONCLUSIONS}

OCLC recognizes that the structure of member participation-whether ILL or contributed cataloging-induces use of, but not contribution to the OLUC. During the last year, OCLC has been exploring ways to resolve this dilemma. Recently it announced a highly innovative restructuring of pricing arrangements called "Contribution Pricing." If implemented as planned in 1990, the structure of "Contribution Pricing" may well provide a foundation for resolving the problems of the present network arrangement.

Briefly, the new scheme makes "least cost participation occur at full database contribution levels" by charging for access (bibliographic searches and holdings displays) and giving credits for contribution (original cataloging, add/delete holdings, create/update LDR's, and ILL lending and requesting). Removal of economic temptation to contribute less and reward for continued full cataloging and holdings contribution are among the benefits the OCLC says should arise from "Contribution Pricing." Whether the reward for contributed cataloging will reflect the real unit cost depends on how realistic OCLC is about paying libraries for the added value they provide to OLUC. Whether the temptation to borrow first and lend later is diminished will depend on whether an accounting mechanism for recovery of the unit cost of lending is provided in the New System for those libraries that wish to use it. OCLC deserves credit for understanding a fundamental flaw inherent in the structure of network participation and praise for a creative new approach to remedying it. ${ }^{31}$ Moreover, the preservation of the national library database, which has figured largely in recent debates over ownership of bibliographic records (e.g., OCLC copyright) and the encouragement of broad participation by libraries in building that database is likely to be dependent on just such a change.

So long as the inducements in our network arrangements reward borrowing, using original cataloging contributed by other libraries, or downloading records without setting the holdings byte-we may expect the present state of affairs to continue. Unequal contribution is a natural and expected outcome. What should surprise us is that many, perhaps most, libraries make an honest effort to contribute their share. The point argued here is that the inducements should have long since been arranged to reward participation. This paper touches on the two most successful examples of cooperation in the electronic environment-shared cataloging and interlibrary lending. There are potential areas of cooperation that we are just beginning to explore including collection development, preservation, and training. These incipient activities will present many of the same issues as those of cataloging and ILL. Thus, the library community faces a significant challenge in resolving the current dilemmas explored in this paper. We should be reminded in this undertaking of the old adage "not to decide, is to decide." 


\section{REFERENCES AND NOTES}

1. Richard M. Dougherty, "Resource Sharing among Research Libraries: How It Ought to Work," Collection Management 9:79-80 (2/3, Summer/Fall 1987); Edward M. Walters, "The Issues and Needs of Local Library Consortium," Journal of Library Administration 8:25-28 (3/4, Fall/Winter 1987); and Irene B. Hoadley, "The Future of Networks and OCLC," Journal of Library Administration 8:85-87 (3/4, Fall/Winter, 1987).

2. JoAn S. Segal, "Networks," in Financing Information Services: Problems, Changing Approaches, and New Opportunities for Academic and Research Libraries, ed. by Peter Spyers-Duran and Thomas W. Mann, Jr. New Directions in Librarianship, no.6, p.141 (Westport, Conn.: Greenwood Press, 1985).

3. Walters, p.15-24.

4. Richard DeGennaro, "Resource Sharing in a Network Environment," Library Journal 104:355 (Feb. 1, 1980); Dougherty, p.80; and Donald E. Riggs, "Networking and Institutional Planning," Journal of Library Administration 8:64 (3/4, Fall/Winter 1987).

5. Thomas W. Shaughnessy, "Management Perspectives on Network Membership," Journal of Library Administration 8:10 (3/4, Fall/Winter 1987).

6. Association of Research Libraries, ARL Statistics, 1987-88 (Washington, D.C.: Association of Research Libraries, 1989), p.42, 49, 54, 55.

7. Paul M. Gherman, "Vision and Reality: The Research Libraries and Networking," Journal of Library Administration 8:52 (3/4, Fall/Winter 1987).

8. Thomas Ballard, "Dogma Clouds the Facts," American Libraries 257 (April, 1985); see also Richard T. Sweeney, "Financial Impacts of Networking and Resource Sharing," Public Library Quarterly 2:91-94 (3/4, Fall/Winter 1981).

9. Walters, p.23.

10. "Pope Encourages Library Network," Catholic Library World 53:418 (May/June, 1982).

11. See, for instance, Kazuko M. Dailey, Grazia Jaroff, and Diana Gray. "RLIN and OCLC-Side by Side: Two Comparisons Studies," in Advances in Library Administration and Organization, ed. by Gerard McCabe, Bernard Kreissman, and W. Carl Jackson, v.1 (Greenwich, Conn.: JAI Press, 1982); Elaine Kemp and others, "A Comparison of OCLC, RLG/RLIN, and WLN," Journal of Library Automation 14:215-30 (3, September, 1981); Danuta A. Nitecki, "Online Interlibrary Services: An Informal Comparison of Five Systems," RQ 20:7-14 (Fall 1981).

12. Sweeney, p.95.

13. Gloria S. Cline, "The High Price of Interlibrary Loan Service" $R Q 27: 80-86$ (Fall 1987); Izabella Taler, "Automated and Manual ILL: Time Effectiveness and Success Rate" Information Technologies and Libraries 1:277-80 (September 1982).

14. De Gennaro, p.353.

15. Herbert S. White, "Interlibrary Loan: An Old Idea in a New Setting" Library Journal 112:53 (July 1987).

16. Ibid.

17. Ibid.

18. Richard T. Miller, "Net Lending: A Follow-Up Report" Show-Me Libraries 38:3-4 (August 1987).

19. See, for instance, Cline, p.80-86.

20. Leslie R. Morris, "Network Prices: Let the Buyer Beware" Technical Services Quarterly 4:57-66 (Summer 1987).

21. Charles T. Horngren, Introduction to Management Accounting (Englewood Cliffs, N.J.: PrenticeHall, Inc., 6th ed., 1984), p.13-16, 685.

22. Martin M. Cummings, "Cost Analysis: Methods and Realities," Library Administration and Management, 3:181-83 (Fall 1989); and Paul Metz, "Special Pleading versus Self-Discipline in the Financing of Public Services" Journal of Academic Librarianship, 14:208-13 (Sept. 1988).

23. D. Kaye Gapen, "Strategies for Networking in the Next Ten Years" Journal of Library Administration 8:118-27 (Fall/Winter 1987).

24. Paul B. Kantor, "The Relation Between Costs and Services in Academic Libraries," p.74. In Financing Information Services: Problems, Changing Approaches, and New Opportunities for Academic and Research Libraries. Ed. by Peter Spyers-Duran and Thomas W. Mann, Jr. New Directions in Librarianship, no.6 (Westport, Conn.: Greenwood Press, 1985). 
25. Paul M. Gherman and Lynn Scott Cochran, "Developing and Using Unit Costs: The Virginia Tech Experience" Library Administration and Management 3:93-96 (2, Spring 1989).

26. White, p.54.

27. For an average number of circulations, see Maurice F. Tauber. ed., Library Binding Manual: A Handbook of Useful Procedures for the Maintenance of Library Volumes (Boston, Mass.: Library Binding Institute, 1972), p.22-24, 36-37, 140.

28. De Gennaro, p.354.

29. Gapen, p.127.

30. Online Computerized Library Center, Inc., OCLC Annual Report, 1987/88 (Dublin, Ohio: OCLC, Inc., 1988), p.1.

31. The description of "Contribution Pricing" provided here is based on handouts and presentations by OCLC staff given during the AMIGOS Bibliographic Council, Inc. Membership Meeting in Dallas, Texas, May 17, 1988, and the OCLC Users Council Meeting in Dublin, Ohio, May 25-26, 1989, both attended by the author. 